\title{
Cervical Microleakage in Giomer Restorations: An In Vitro Study
}

\author{
Basanagouda S Patil ${ }^{1}$, Laxmikant Kamatagi ${ }^{2}$, Hrishikesh Saojii ${ }^{3}$, Naveen Chabbra ${ }^{4}$, Shruti Mutsaddi ${ }^{5}$
}

\begin{abstract}
Aim: The purpose of this in vitro study was to determine the effect of different composite placement techniques on gingival microleakage of giomer restorations.

Materials and methods: Sixty class II preparations were created in 30 extracted molar teeth with cervical margins 1 mm below the cementoenamel junction. The teeth were divided into three groups of 10 teeth each. In group I, teeth were restored with open sandwich technique using Beautifil II and Beautifil II Flow. In group II, teeth were restored with snowplow technique using Beautifil II and Beautifil Flow. In group III, teeth were restored with oblique increment technique using Beautifil II. After thermocycling and immersion in $2 \%$ methylene blue, the teeth were sectioned and dye penetration was evaluated.

Results: Statistically significant reduction in microleakage was found along the gingival walls in snowplow restorations compared to sandwich restoration and oblique increment restorations.

Clinical significance: Microleakage was reduced along the gingival walls in snowplow restorations.

Conclusion: Microleakage was significantly lower in the snowplow restorations.

Keywords: Microleakage, Oblique increment restorations, Sandwich restoration and snowplow restorations.

The Journal of Contemporary Dental Practice (2020): 10.5005/jp-journals-10024-2744
\end{abstract}

\section{INTRODUCTION}

Marginal discoloration, secondary caries, restoration failure, and pulpitis are the results of insufficient sealing. Hence, the interface between the restoration and dental hard tissue is an area of clinical concern. ${ }^{1}$ One of the weakest aspects of class II composite resin restorations is microleakage at the gingival margin of mesial and distal cavity boxes.

To reduce microleakage, separate incremental insertion modes have been tried. This helped in improving the in-depth curing of composites and minimizing the effect of confinement on contraction stress development. ${ }^{2-4}$ Layering method of composite placement has advantages over bulk method of placement of composites. Hence, the small volume of material is used for a lower cavity configuration factor and minimal contact with the opposing cavity walls during polymerization. ${ }^{5}$

A study by Behle mentioned and shared the comparison of the effects of horizontal, oblique, and vertical layering techniques on microtensile bond strength to dentin, and they showed that acceptable bond strengths were observed only when the first increment was bonded horizontally to the cavity floor. ${ }^{6}$

Microleakage involves many factors, such as dimensional changes in materials due to polymerization shrinkage, thermal contraction, absorption of water, mechanical stress, and dimensional changes in tooth structure. ${ }^{7}$

Flowable composites have been recommended as liners beneath composite resins due to their low viscosity and increased elasticity and wettability.

Flowable composite resin was postulated to have the ability to reduce the microleakage. It has been recommended as the first increment for class II restorations because of its better flow, easy application in areas that are difficult to access, and adaptation to irregular surface of the cavity preparation..$^{8,9}$
1,2Department of Conservative Dentistry and Endodontics, PM
Nadagouda Memorial Dental College and Hospital, Bagalkot,
Karnataka, India
${ }^{3}$ Department of Conservative Dentistry and Endodontics, Bharati
Vidyapeeth Dental College and Hospital, Navi Mumbai, Maharashtra,
India
${ }^{4}$ Department of Conservative Dentistry and Endodontic, KM Shah
Dental College and Hospital, Vadodara, Gujarat, India
${ }^{5}$ Department of Oral Pathology, Subbaiah Dental College, Shivamogga, Karnataka, India

Corresponding Author: Laxmikant Kamatagi, Department of Conservative Dentistry and Endodontics, PM Nadagouda Memorial Dental College and Hospital, Bagalkot, Karnataka, India, Phone: +91 9686830050, e-mail: Ikamatagi@gmail.com

How to cite this article: Patil BS, Kamatagi L, Saojii H, et al. Cervical Microleakage in Giomer Restorations: An In Vitro Study. J Contemp Dent Pract 2020;21(2):161-165.

Source of support: Nil

Conflict of interest: None

The use of cured increment of flowable resin composite in conjunction with class II resin composite restorations has shown mixed results in microleakage studies.

On the gingival and proximal walls, a flowable resin layer was applied, and this was polymerized with the initial gingival traditional composite layer, which was applied in the cavity. Most of the flowable composite is displaced by the composite resin. Just a small quantity of the composite remained in high-viscosity composite resin areas of the cavity where they did not fully adhere to the cavity walls. ${ }^{10,11}$

(C) The Author(s). 2020 Open Access This article is distributed under the terms of the Creative Commons Attribution 4.0 International License (https://creativecommons. org/licenses/by-nc/4.0/), which permits unrestricted use, distribution, and non-commercial reproduction in any medium, provided you give appropriate credit to the original author(s) and the source, provide a link to the Creative Commons license, and indicate if changes were made. The Creative Commons Public Domain Dedication waiver (http://creativecommons.org/publicdomain/zero/1.0/) applies to the data made available in this article, unless otherwise stated. 
The snowplow technique involves the placement of a layer of flowable composite on the pulpal floor and gingival margin of the proximal box of a posterior composite resin restoration. ${ }^{12}$

In the open sandwich technique, the caries' lesion and class II cavity preparation extend near to or apical to the cementoenamel junction (CEJ). If the restoration is exposed to the oral environment at the base of the restoration, it is known as open sandwich technique. ${ }^{13}$

In oblique increment technique, the composite resin is placed inside the cavity in many increments. Then one by one the increment is photocured double the time. This was first started through the cavity walls and next to the occlusal surface, so that each increment is in contact only with the bottom and one side wall of the cavity. ${ }^{14}$

This study evaluated the effect of snowplow technique, open sandwich technique, and oblique increment technique in reducing the microleakage class II restorations with gingival margins on the root surface.

\section{Materials and Methods}

Thirty intact extracted molars devoid of caries, restoration, and cracks were chosen for the study. Standardized class II box only cavities were prepared on either of the proximal surfaces with rounded internal line angles and a cavosurface margin at $90^{\circ}$ to the tooth surface. The dimensions of the cavities were as follows: buccolingual width $=3 \mathrm{~mm}$, mesiodistal width $=2 \mathrm{~mm}$, and gingival floor $=1 \mathrm{~mm}$ below the cementoenamel junction. The dimensions of the cavities were verified with a periodontal probe. Cavity preparations were performed using a diamond dome-shaped fissure bur and cooled in water a high-speed air turbine handpiece. The bur was replaced after every tenth cavity preparation.

The thirty teeth were divided into three groups $(n=10)$. Around the tooth universal metal matrix band was used, which was externally prepared by applying a low fusing compound that helped to maintain the adaptation of the band to the cavity margins.

Each cavity was cleaned with water spray and air-dried for 5 seconds. The self-etch adhesive is applied to the cavity walls and the air was thinned and cured for 20 seconds.

Group I: Teeth were restored with open sandwich technique using Beautifil II and Beautifil II Flow and cured for 40 seconds.

Group II: Teeth were restored with snowplow technique using Beautifil II and Beautifil II Flow and cured for 40 seconds.

Group III: Teeth were restored with oblique increment procedure using Beautifil II and cured for 40 seconds.

The teeth were stored in distilled water for 1 week, before the cervical margins were finished with fine diamond bur under water cooling and polished with a sof-lex disc. The restored teeth were subjected to 500 thermocycles of between $5^{\circ} \mathrm{C}$ and $55^{\circ} \mathrm{C}$ in water baths, with a 30 -second dwell time. ${ }^{15}$ Apical foramina of the teeth were sealed with sticky wax. Two layers of nail varnish were applied $1 \mathrm{~mm}$ away from the cavity margins. Samples were then immersed in a $2 \%$ methylene blue solution for 24 hours at $37^{\circ} \mathrm{C} .^{15}$ After which teeth were rinsed with tap water for 5 minutes and then scrubbed to remove the nail varnish. Each tooth was then sectioned mesiodistally with diamond disc, and the extent of microleakage was scored using the international standard organization (ISO) microleakage scoring system. Sectioned restorations were examined under a stereomicroscope (Wild M3C, Heerburg, Switzerland) at $25 \times$ magnification. The extent of the cervical microleakage was recorded.
Cervical dye penetration score: $:^{10}$

Score 0: No dye penetration (Fig. 1A).

Score 1: Dye penetration into $1 / 2$ of the cervical wall (Fig. 1B)

Score 2: Dye penetration into all the cervical wall (Fig. 1C)

Score 3: Dye penetration into cervical and axial walls (Fig. 1D)

\section{Results}

Comparison of open sandwich technique, snowplow restorations, and oblique increment technique with respect to microleakage by Kruskal-Wallis analysis of variance test revealed that $p=0.0002^{*}$ which is statistically significant in all three test groups (Table 1 and Fig. 2).

Pair-wise comparison was done using Mann-Whitney test (open sandwich technique vs snowplow technique, $Z=-2.3939$, $p=0.0166^{*}$; open sandwich technique vs oblique increment technique, $Z=-1.9746, p=0.04831^{*}$; and snowplow technique vs oblique increment technique, $Z=-3.6788, p=0.0002^{*}$ ) (Table 1 and Fig. 2).

According to the comparison, snowplow restoration showed least microleakage followed by open sandwich restoration which is followed by oblique increment technique.

\section{Discussion}

Flowable composites are put forth as liners under class II resin composite restorations due to their low viscosity, elasticity, and wettability. ${ }^{16}$ Additionally, thermal expansion of these materials has a coefficient similar to tooth tissue. ${ }^{17}$

According to Hooke's law:

Shrinkage stress $=$ shrinkage $\times$ modulus of elasticity

A high modulus of elasticity results in high shrinkage stress during polymerization shrinkage. As a consequence, marginal gap increases. Flowable composite resins exhibit a substantially lower modulus of elasticity that enables increased elastic deformation in which to flex and absorb polymerization shrinkage stresses. This procedure reduces microleakage and stress by $18-50 \% .{ }^{6,18}$

Flowable composites have a coefficient of thermal expansion similar to that of tooth structure. The use of fluid layer may have a low C-factor. The lower the C-factor, the lower the internal stress. When the internal stress is low, there is less competition between contraction forces arising from monomer conversion and the efforts of the adhesive agent to keep the composite bonded to the surface. ${ }^{6}$

Because of higher resin content, flowable composites demonstrate up to three times greater polymerization shrinkage than do standard hybrid composite formulations. ${ }^{19,20}$ Marginal microleakage increased with the increasing thickness of flowable composite lining, which is due to increasing proportion of monomer, resulting in higher polymerization shrinkage value. ${ }^{21,22}$

This study showed the clinical efficiency of low-viscosity composite resins by reducing marginal cervical microvoids. Second, the low viscosity fluid resin layer helps to improve composite adhesion to the cavity by diminishing the contact angle between the cavity walls and the restoration material, thus reducing superficial strains and stimulating adequate material adjustment to the cavity edges. ${ }^{23}$

In snowplow technique, a small amount of flowable composite can be found in such areas of the cavity where the high-viscosity resin composite does not completely adapt to the cavity wall, which may lead to voids. As in this procedure both flowable and 

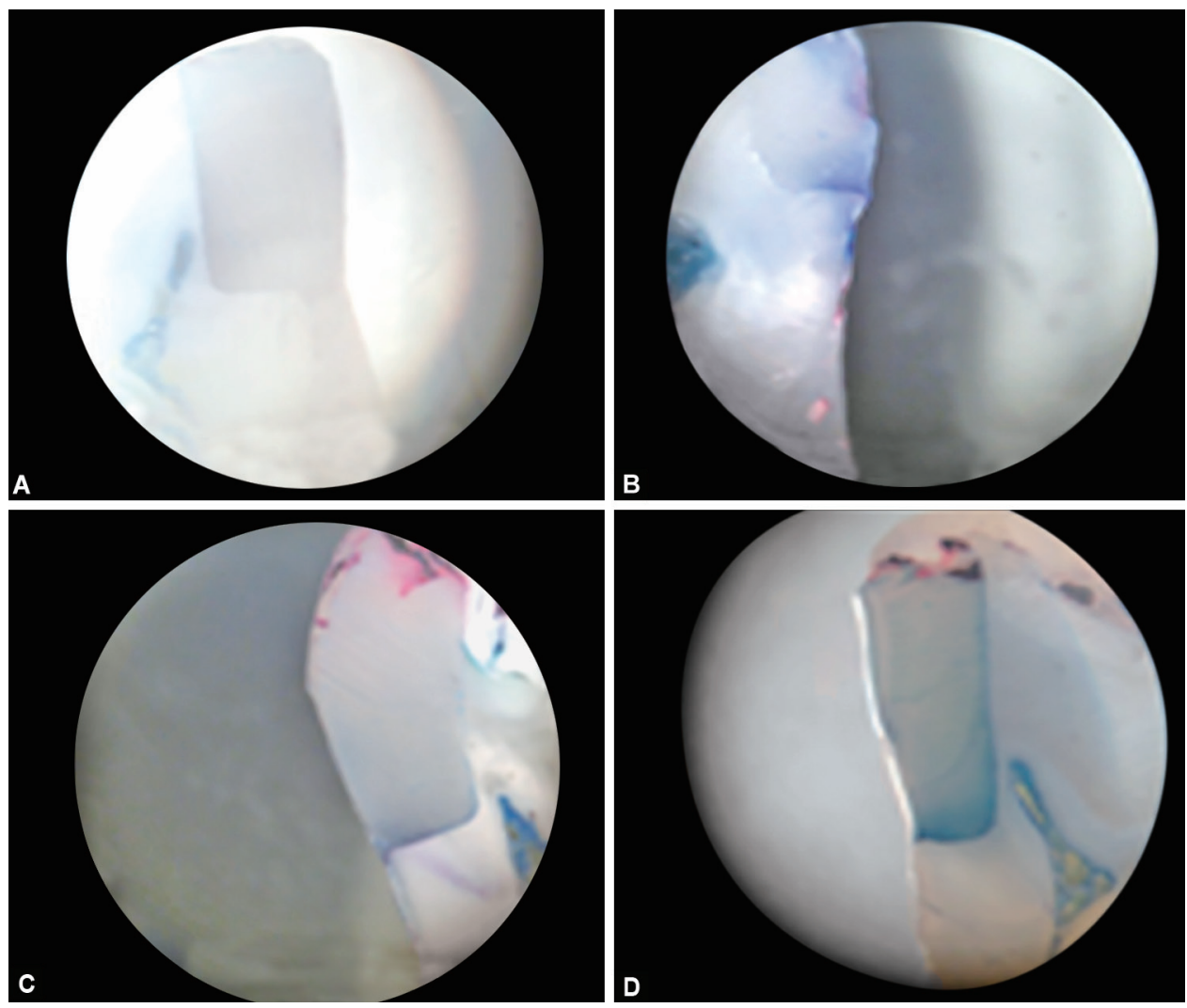

Figs 1 A to D: (A) Score 0: no dye penetration; (B) Score 1: dye penetration into $1 / 2$ of the cervical wall; (C) Score 2: dye penetration into all the cervical wall; (D) Score 3: dye penetration into cervical and axial wall

Table 1: Comparison of open sandwich technique, snowplow restorations, and oblique increment techniques with respect to microleakage by Kruskal-Wallis analysis of variance (ANOVA)

\begin{tabular}{|c|c|c|c|c|c|c|c|c|c|}
\hline Group & No leakage & $\%$ & Half gingival wall & $\%$ & Full gingival wall & $\%$ & Till axial wall & $\%$ & Total \\
\hline Open sandwich technique & 2 & 10.0 & 10 & 50.0 & 7 & 35.0 & 1 & 5.0 & 20 \\
\hline Snowplow technique & 9 & 45.0 & 8 & 40.0 & 3 & 15.0 & 0 & 0.0 & 20 \\
\hline Oblique increment technique & 1 & 5.0 & 5 & 25.0 & 9 & 45.0 & 5 & 25.0 & 20 \\
\hline Total & 12 & 20.0 & 23 & 38.3 & 19 & 31.7 & 6 & 10.0 & 60 \\
\hline
\end{tabular}

Kruskal-Wallis ANOVA, $H=17.1203, p=0.0002^{*}$

Pair-wise comparison by Mann-Whitney $U$ test

Open sandwich technique vs snowplow technique, $Z=-2.3939, p=0.0166^{*}$

Open sandwich technique vs oblique increment technique, $Z=-1.9746, p=0.04831^{*}$

Snowplow technique vs oblique increment technique, $Z=-3.6788, p=0.0002^{*}$

restorative composites are co-cured, the remaining flowable composite will absorb the volumetric changes and can stretch or flow to allow stress relaxation. ${ }^{24}$ On this basis, it is assumed that co-curing of flowable and restorative composites would also result in less polymerization shrinkage and subsequently less microleakage.

The properties of the Beautifil II are closer to the tooth structure and fluoride uptake is from the pre-reacted giomer calcium fillers. This may be explained by the fact that beautibond employs an interesting chemical approach for maximizing the union (mechanic) and bonding (chemical) to tooth substrates. Beautibond contains a monomer of carboxylic acid that promotes bonding to dentin and phosphonic acid to generate bonding to enamel.

Because of higher resin content, the flowable composites demonstrate up to three times greater polymerization shrinkage than do standard hybrid composite formulations. ${ }^{25}$
This adversely impacts the adhesion of composite to the cavity preparation, as higher polymerization shrinkage and polymerization shrinkage stress have been shown to significantly decrease the bond strength. ${ }^{18,26}$

As an example, different dye tracers are available for use in microleakage studies. Methylene blue dye $0.5 \%$ was chosen as the agent of dye penetration to measure microleakage because it is simple, inexpensive, and does not require the use of complex laboratory equipment. The particle size of this dye is less than the internal diameter of the dentinal tubules (1-4 $\mu \mathrm{m})$, so it is able to show dentin permeability. Recently, Behle et al. reported that no significant difference was observed in the intratubular penetration between basic fuchsin, silver nitrate, and methylene blue. ${ }^{6}$

Since methylene blue has small surface area (approximately $0.52 \mathrm{~nm}^{2}$ ), it may lead to an overestimation of leakage at the tooth-restoration interface, particularly with self-etch adhesives in 


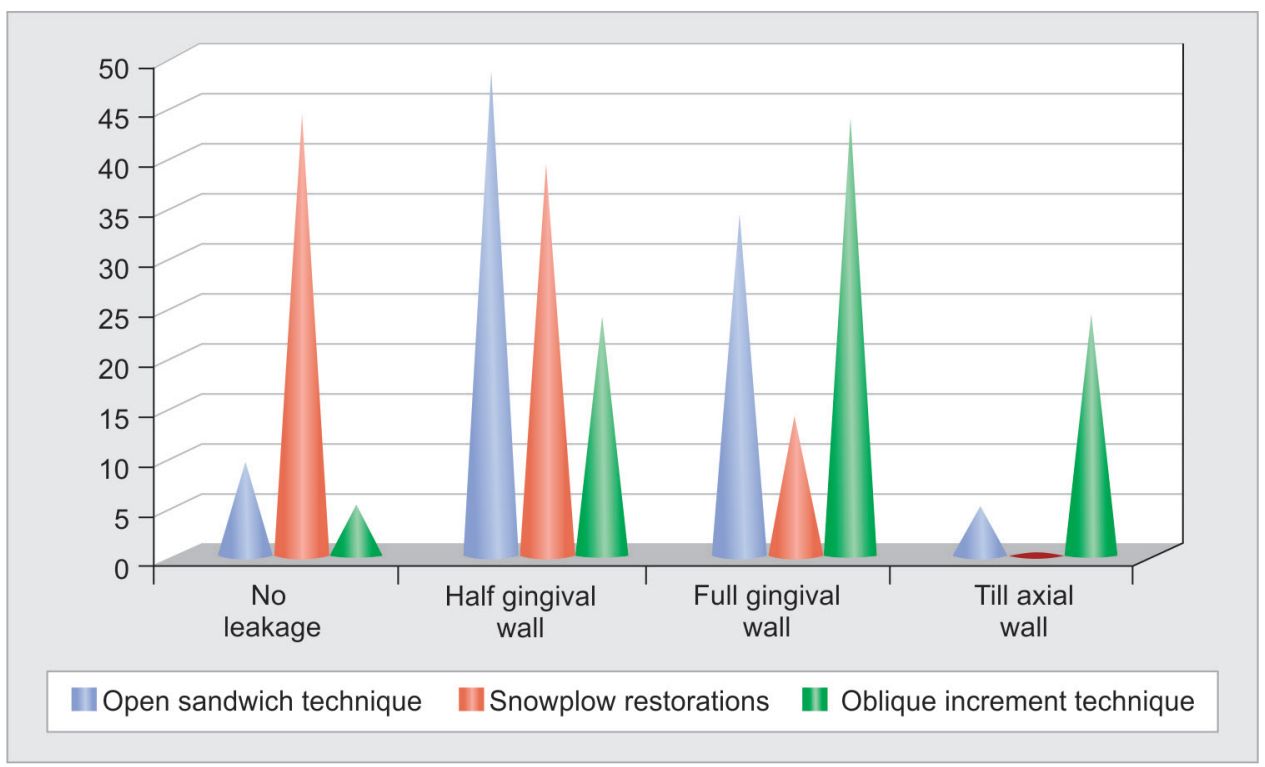

Fig. 2: Comparison of micoleakage in all three composite placement techniques

relation to their increased hydrophilicity. ${ }^{27}$ The use of the methylene blue tracer led to higher microleakage scores compared to other microscopic evaluations.

The water storage and thermocycling samples helps to replicate oral environment. A common artificial aging technique is achieved with the help of thermocycling, which is also a simulation of clinical aging. Some authors reported the absence of any influence of thermocycling on microleakage ${ }^{28}$ while others show an increase in microleakage at the cementum-dentin-restoration interface after thermal stress. ${ }^{29}$

The placement techniques proved to be important for longevity of these materials. Failure associated with these restorations is invariably due to the use of improper technique and microleakage at the gingival margin.

\section{Conclusion}

Microleakage was clinically significantly lower in snowplow restorations compared to the open sandwich restoration, which has lower microleakage than the oblique increment technique.

Our future scope is snowplow restorations can provide the best marginal seal clinically.

\section{References}

1. Kidd EA. Microleakage: a review. J Dent 1976;4(5):199-206. DOI: 10.1016/0300-5712(76)90048-8.

2. Donly KJ, Wild TW, Jensen ME. Posterior composite class II restorations: in vitro comparison of preparation designs and restoration techniques. Dent Mater 1990;6(2):88-93. DOI: 10.1016/ S0109-5641(05)80036-3.

3. Félix SA, González-López S, Mauricio PD, et al. Effects of filling techniques on the regional bond strength to lateral walls in class I cavities. Oper Dent 2007;32(6):602-609. DOI: 10.2341/06-170.

4. Duarte Jr S, Dinelli W, da Silva MH. Influence of resin composite insertion technique in preparations with a high C-factor. Quintessence Int 2007;38(10):829-835.

5. Giachetti L, Scaminaci Russo D, Bambi C, et al. A review of polymerization shrinkage stress: current techniques for posterior direct resin restorations. J Contemp Dent Pract 2006;17(4):79-88. DOI: 10.5005/jcdp-7-4-79.
6. Behle C. Flowable composite: Properties and applications. Pract Periodontics Aesthet Dent 1998;10(3):347, 350-351.

7. Staninec M, Mochizuki A, Tanizaki K, et al. Interfacial space, marginal leakage and enamel cracks around composite resins. Oper Dent 1986;11(1):14-24.

8. Olmez A, Oztas N, Bodur $\mathrm{H}$. The effect of flowable resin composite on microleakage and internal voids in class II composite restoration. Oper Dent 2004;29(6):713-719.

9. Petzfeldt A, Asmussen E. Composite restoration: influence of flowable and self curing resin composite liningson microleakage in vitro. Oper Dent 2002;27(6):569-575.

10. Bagis $\mathrm{YH}$, Baltacioglu IH, Kahyaogullari S. Comparing microleakage and the layering methods of silorane-based resin composite in wide Class II MOD cavities. Oper Dent 2009;34(5):578-585. DOI: 10.2341/08073-LR.

11. Summitt JB, Robbins JW, Hilton TJ, et al. Fundamentals of operative dentistry A Contemporary Approach, 3rd ed., 2006. p. 316.

12. Porosity formation and microleakage of composite resins using the snowplow technique. A Presicci-2012 - apps.dti c.mil.

13. Resin-modified glass ionomer: The open sandwich technique. http:// www.dentaleconomics.com.

14. Chandrasekhar V, Rudrapati L, Badami V, et al. Incremental techniques in direct composite restoration. J Conserv Dent 2017;20(6):386-391. DOI: 10.4103/JCD.JCD_157_16.

15. Malik N, Lin SL, Rehman NA, et al. Effect of liners on microleakage in class II composite restoration (Pengaruh Pelapik Tampalan pada Kebocoran Mikro di Komposit Restorasi Kelas II). Sains Malaysiana 2013;42(1):45-51.

16. Lindberg A, Dijken JW, Lindberg M. Nine year evaluation of a polyacid-modified resin composite/resin composite open sandwich technique in class II cavities. J Dent 2007;35(2):124-129. DOI: 10.1016/ j.jdent.2006.06.003.

17. Chuang SF, Liu JK, Jin YT. Microleakage and internal voids in class II composite restorations with flowable composite linings. Oper Dent 2001;26(2):193-200.

18. Kemp-Sholte CM, Davidson CL. Marginal integrity related to bond strength and strain capacity of composite resin restorative systems. J Prosthet Dent 1990;64(6):658-664. DOI: 10.1016/0022-3913(90) 90291-J.

19. Sadeghi M. The effect of fluid composite as gingival layer on microleakage of class II composite resorations. Dent Res J 2007;4(1):40-47. 
20. Labella R, Lambrechts $P$, Van Meerbeek B, et al. Polymerization shrinkage and elasticity of flowable composites and filled adhesives. Dent Mater 1999;15(2):128-137. DOI: 10.1016/S0109-5641(99) 00022-6.

21. Yoshikawa T, Sano H, Burrow MF, et al. Effects of dentin depth and cavity configuration on bond strength. J Dent Res 1999;78(4): 898-905. DOI: 10.1177/00220345990780041001.

22. Hilton T, Quin R. Marginal leakage of class 2 composite/flowable restorations with varied cure technique (abstract 502). J Dent Res 2001;80:589.

23. Pomohaci DD, Radu TM, Teodorovici P, et al. Preventing marginal microleakage in class ii restoration using bioadhesive materials. J Romanian Med Dent 2009;13(3):63-68.

24. Alster D, Feilzer AJ, de Gee AJ, et al. The dependence of shrinkage stress reduction of porocity concentration in thin resin layers. J Dent Res 1992;71(9):1619-1622. DOI: 10.1177/00220345920710091401.
25. Chuang SF, Liu JK, Chao CC, et al. Effect of flowable composite lining and operator experience on microleakage and internal voids in class II composite restorations. J Prosthet Dent 2001;85(2):177-183. DOI: 10.1067/mpr.2001.113780.

26. Nikolaenko SA, Lohbauer U, Roggendorf M, et al. Influence of C-factor and layering technique on microtensile bond strength to dentin. Dent Mater 2004;20(6):579-585. DOI: 10.1016/j.dental.2003.08.001.

27. Fabianelli A, Sgarr A, Goracci C, et al. Microleakage in class II restorations: open vs closed centripetal build-up technique. Oper Dent 2010;35(3):308-313. DOI: 10.2341/09-128-L.

28. Doerr CL, Hilton TJ, Hermesch CB. Effect of thermocycling on the microleakage of conventional and resin modified glass ionomer. Am J Dent 1996;9(1):19-21.

29. Yap AU. Effects of storage, thermal and load cycling on a new reinforced glass-ionomer cement. J Oral Rehabil 1997;25(1):40-44. DOI: 10.1046/j.1365-2842.1998.00192.x. 